\title{
Video-Assisted Thoracic Surgery
}

National Cancer Institute

\section{Source}

National Cancer Institute. Video-Assisted Thoracic Surgery. NCI Thesaurus. Code C63704.

Thoracic surgery that is aided by the use of a video camera. 